\title{
Ranking and transformation error assessment of shear strength parameters correlations
}

\author{
Waled Daoud ${ }^{1,2,3^{*}}$, Kiyonobu Kasama ${ }^{2}$, Naser Saleh ${ }^{3}$ and Abdelazim Negm ${ }^{1}$
}

\author{
*Correspondence: \\ walid.dawoud@ejust.edu.eg; \\ walid.dawoud@feng.bu.edu.eg \\ ${ }^{1}$ Egypt-Japan University \\ of Science and Technology, \\ P.O. Box 179, New Borg El-Arab \\ City 21934, Egypt \\ Full list of author information \\ is available at the end of the \\ article
}

\begin{abstract}
Shear strength is responsible for soil ability to withstand applied loads and considered the most important engineering properties of soil. Shear strength can be measured directly in the field or in the laboratory, however many empirical correlations were developed to predict shear strength from simple basic and index properties of soil. The main reasons for using these correlations that direct measurements are costly, time consuming, and not always applicable. The correlated shear strength parameter deviates from its actual value, by a transformation error, causing larger uncertainty that affects the overall design. The current commonly used transformation error values have shortcomings that warrant the need for further research. To offer avenues for improving the current values, a database contains geotechnical investigation results for 5087 boreholes collected from Egypt, UAE, Iraq, and Indonesia were created. The database served to assess inherent variability, measurement error, and transformation error more consistently. The most commonly used empirical correlations were ranked based on amended Theil inequality coefficient method, then the transformation error was determined using uncertainty propagation combined with the second moment probabilistic method (RUP-SMP). The adapted methodology can be used as standard procedures to evaluate different empirical correlations for other geotechnical properties. Framework for combining the predicted transformation error with other uncertainties was introduced to determine the overall uncertainty in shear strength parameters.
\end{abstract}

Keywords: Geotechnical variability, Transformation error, Empirical correlations evaluation, Correlations ranking, Uncertainty propagation

\section{Background}

In contrast to other engineering materials, soil resist applied loads by means of friction and cohesion between particles that is known as shear strength. The shearing resistance of soil depends mainly on soil composition, stress history, strain, strain rate, voids ratio, cohesion, and friction between particles [17]. A functional form that considers all these parameters are too complex and several simplifications were done to assess the shear strength of soil. The most widely used functional form of shear strength is the MohrCoulomb equation, which simplify the soil shear strength to depend only on cohesion, internal friction angle, and confining stress [2]. 
Soil cohesion and internal friction angle, the shear strength parameters, can be measured directly in the field or in laboratory. Direct measurement of shear strength parameters is costly, time consuming, and not always applicable [23] that necessitate the development and use of empirical correlations. These empirical correlations were derived from data fitting for a specific site conditions that may cause deviation of the correlated soil properties if used in other sites. This deviation of the correlated values from its real value is known as transformation error. Transformation error is considered one of the main three sources of uncertainty in geotechnical properties. The other sources are inherent variability and measurement errors. Inherent variability is originated mainly from different in situ geologic processes in contrast to measurement error that is caused by random sampling and testing characteristics [24].

For major geotechnical projects, such as offshore piles, deterministic design is not always enough and further consideration of geotechnical uncertainties is deemed necessarily [22]. Several methods were proposed to consider these uncertainties, but its implementation is a challenging task due to the difficulty of assessing the uncertainties in soil properties. The current commonly used transformation error values had shortcomings that warrant the need for further research. Main shortcomings are: it didn't cover all soil types; it covered only a very limited amount of empirical correlations; it depends mainly on literature values; and different sources of uncertainties were combined although it was originated from different soil conditions. To overcome these shortcomings and to offer avenues for improving the current transformation error values, a database contains geotechnical investigation results for 5087 boreholes collected from Egypt, UAE, Iraq, and Indonesia was created. The database served to assess inherent variability, measurement error, and transformation error more consistently. In addition, it offered unified shear strength parameters estimation from different correlations.

In this paper, the most commonly used shear strength correlations were ranked based on both position conformity and trend conformity using amended Theil inequality coefficient (ATIC) method as proposed by Song et al. [28]. ATIC method considers both trend and position conformities between the correlated and measured values enabling more accurate ranking than other statistical ranking measures. Correlations ranking served to assess the most credible correlation to be used for shear strength parameters determination at specific site condition. The transformation error was determined using rule-based uncertainty propagation combined with second moment probabilistic method (RUP-SMP). The deduced transformation error values can be used as guidance in the absence of other, more accurate, site-specific values. Framework for combining the predicted transformation error with other uncertainties was introduced that can be used to determine the overall uncertainty of shear strength parameters.

\section{Materials and resources}

\section{Geotechnical database}

Subsurface investigation reports were collected from reputable geotechnical firms in Egypt, UAE, Iraq, and Indonesia. The collected reports contained field and laboratory tests results for more than 35,000 boreholes collected during the last 3 years. The most recent boreholes were classified based on project type and completeness of information. The most reliable boreholes were entered with consistent and unified units 
into the geotechnical database. The data was checked with the source data to ensure the quality and consistency of information. Checking was carried out by comparing between entered and source data to insure that the required data are correctly and completely entered. Checking took into consideration the mandatory fields, type of data, and needed data for the research. The database was designed to have 98 tables to enable future extension of the entered data. To serve the current research, only 27 tables were filled with 5087 boreholes. In addition, 2 extra tables were entered for data quality checking to store the path of the borehole documents.

\section{Shear strength correlations}

Shear strength correlation development was started as early as forty of the twentieth century and new correlations are still being developed. Most of correlations for cohesive soils are based on soil plasticity because cohesion depends mainly on clay mineral types, clay particle size, clay proportion, and bond between particles. For internal friction angle, the correlations are based on dry density and relative density because shearing resistance depends mainly on particle size distribution, shape of particles, and surface texture [11]. Table 1 summarizes the used empirical correlation for undrained cohesion and Table 2 for drained internal friction angle. Some of these correlations were modified from its original form to be in consistent units by using standard unit conversion factors.

\section{Adapted methodology}

Because of the importance and popularity of using shear strength correlations, the geotechnical community should pay more attention to the credibility of these correlations. Analyzing the degree of consistency between the correlated and observed values is a probable method of correlation validation. Amended Theil inequality coefficient (ATIC) method as introduced by Song et al. [28] will be used to rank different shear strength correlations based on the difference in position and trend between the correlated and observed values. The transformation error of each correlation will be determined using rule-based uncertainty propagation (RUP) as demonstrated by Farrance and Frenkel [6] combined with the second moment probabilistic method (SMP) proposed by Phoon et al. [25].

\section{Correlations ranking}

Theil inequality coefficient (TIC) was widely used for validating the simulation model in industrial and telecommunication applications since 1977 until now. TIC method does not have any restrictions on the correlated and observed values, its principal is simple, and easy to be applied. For number $(n)$ of observed values $\left(x_{0}\right)$ and correlated values $\left(x_{c}\right)$, the TIC is given by:

$$
C\left(X_{o}, X_{c}\right)=\frac{\sqrt{\sum_{i=1}^{n}\left(x_{o}(i)-x_{c}(i)\right)^{2}}}{\sqrt{\sum_{i=1}^{n} x_{o}(i)^{2}+} \sqrt{\sum_{i=1}^{n} x_{c}(i)^{2}}}
$$

where, $C\left(X_{o}, X_{c}\right)$ is the TIC. 
Table 1 Undrained cohesion empirical correlations

\begin{tabular}{|c|c|c|c|c|c|}
\hline Cor. ID & Name & Formulae & Soil type & Reference & Notes \\
\hline $\mathrm{C} 01$ & $\begin{array}{l}\text { Bjerrum and } \\
\text { Simons [1] }\end{array}$ & $C_{u}=\sigma_{o}^{\prime}\left(0.45 \sqrt{I_{p}}\right), \quad I_{p}>0.5$ & $\begin{array}{l}\text { Normally } \\
\text { consolidated } \\
\text { clay }\end{array}$ & [2] & Scatter: $\pm 25 \%$ \\
\hline $\mathrm{CO2}$ & $\begin{array}{l}\text { Bjerrum and } \\
\text { Simons [1] }\end{array}$ & $C_{u}=\sigma_{0}^{\prime}\left(0.18 \sqrt{I_{L}}\right), \quad I_{L}>0.5$ & $\begin{array}{l}\text { Normally } \\
\text { consolidated } \\
\text { clay }\end{array}$ & [2] & Scatter: $\pm 30 \%$ \\
\hline $\mathrm{CO3}$ & $\begin{array}{l}\text { Skempton and } \\
\text { Henkel [27] }\end{array}$ & $C_{u}=\sigma_{o}^{\prime}(0.11+0.37 / p)$ & $\begin{array}{l}\text { Normally } \\
\text { consolidated } \\
\text { clay }\end{array}$ & {$[27]$} & - \\
\hline $\mathrm{CO} 4$ & $\begin{array}{l}\text { Karlsson and Viberg } \\
\text { [13] }\end{array}$ & $C_{u}=\sigma_{0}^{\prime}\left(0.5 w_{L}\right), \quad w_{L}>0.2$ & $\begin{array}{l}\text { Normally } \\
\text { consolidated } \\
\text { clay }\end{array}$ & [2] & Scatter: $\pm 30 \%$ \\
\hline C05 & Edil and Benson [5] & $C_{u}=\frac{144.9}{e^{1.72 L}}$ & $\begin{array}{l}\text { Cohesive soils in } \\
\text { Southeastern } \\
\text { Wisconsin }\end{array}$ & [5] & $R^{2}=0.58$ \\
\hline C06 & Edil and Benson [5] & $C_{u}=\frac{191.4}{e^{3 W_{L}}}$ & $\begin{array}{l}\text { Cohesive soils in } \\
\text { Southeastern } \\
\text { Wisconsin }\end{array}$ & {$[5]$} & $R^{2}=0.38$ \\
\hline $\mathrm{CO}$ & Edil and Benson [5] & $C_{u}=\sigma_{O}^{\prime}\left(\frac{0.5}{e^{1.11 L}}\right)$ & $\begin{array}{l}\text { Cohesive soils in } \\
\text { Southeastern } \\
\text { Wisconsin }\end{array}$ & {$[5]$} & $R^{2}=0.43$ \\
\hline C08 & $\begin{array}{l}\text { Worth and Houlsby } \\
\text { (1985), Mitchell } \\
\text { and Soga [17] }\end{array}$ & $C_{u}=\sigma_{o}^{\prime}(0.129+0.435 / p)$ & General & {$[17]$} & - \\
\hline CO9 & Roy and Dass [26] & $C_{u}=98.07\left(0.131 \gamma_{b}-0.138\right)$ & $\begin{array}{l}\text { Cohesive soils in } \\
\text { Sisra, India }\end{array}$ & [26] & $R=0.84$ \\
\hline $\mathrm{C} 10$ & Roy and Dass [26] & $C_{u}=98.07\left(0.178 \gamma_{d}-0.198\right)$ & $\begin{array}{l}\text { Cohesive soils in } \\
\text { Sisra, India }\end{array}$ & [26] & $R=0.76$ \\
\hline $\mathrm{C} 11$ & Roy and Dass [26] & $C_{u}=98.07(0.3 w-0.059)$ & $\begin{array}{l}\text { Cohesive soils in } \\
\text { Sisra, India }\end{array}$ & {$[26]$} & $R=0.65$ \\
\hline $\mathrm{C} 12$ & $\begin{array}{l}\text { Mitchell and Soga } \\
{[17]}\end{array}$ & $C_{u}=\frac{1}{\left(I_{L}-0.21\right)^{2}}$ & General & {$[17]$} & - \\
\hline $\mathrm{C} 13$ & Kang et al. [12] & $C_{u}=\sigma_{o}^{\prime}\left(I_{p}^{2}-1.12 I_{p}+0.4398\right)$ & $\begin{array}{l}\text { Low plasticity } \\
\text { clay }\end{array}$ & [12] & $R=0.695$ \\
\hline $\mathrm{C} 14$ & Kang et al. [12] & $C_{u}=\sigma_{o}^{\prime}(0.7575-0.74 / \rho)$ & $\begin{array}{l}\text { Highly plastic } \\
\text { clay }\end{array}$ & {$[12]$} & $R=0.608$ \\
\hline $\mathrm{C} 15$ & Hara et al. [8] & $C_{u}=98.07\left(0.297 N^{0.72}\right)$ & $\begin{array}{l}\text { Alluvial clays in } \\
\text { Japan }\end{array}$ & [8] & $R=0.93$ \\
\hline C16 & Terzaghi et al. [31] & $C_{u}=3.6 \mathrm{~N}$ & Cohesive soil & [31] & \\
\hline $\mathrm{C} 17$ & Nixon [19] & $C_{u}=11.965 \mathrm{~N}$ & Clay & [19] & \\
\hline $\mathrm{C} 18$ & Décourt [4] & $C_{u}=12.455 \mathrm{~N}$ & Clay & [4] & \\
\hline C19 & $\begin{array}{l}\text { Hettiarachchi and } \\
\text { Brown [10] }\end{array}$ & $C_{u}=4.1 N_{60}$ & Cohesive soil & [10] & \\
\hline $\mathrm{C} 20$ & $\begin{array}{l}\text { Nassaji and Kalan- } \\
\text { tari [18] }\end{array}$ & $C_{u}=1.6 \mathrm{~N}+15.4$ & $\begin{array}{l}\text { Tehran fine } \\
\text { grained soil }\end{array}$ & [18] & $R=0.72$ \\
\hline
\end{tabular}

$C_{u}$ soil undrained cohesion $(\mathrm{kPa}), w_{L}$ liquid limit (decimal entry), $I_{P}$ plasticity index (decimal entry), $\sigma_{o}^{\prime}$ effective overburden pressure $(\mathrm{kPa}), I_{L}$ liquidity index (decimal entry), $\gamma_{b}$ soil bulk density $\left(\mathrm{g} / \mathrm{cm}^{3}\right), \gamma_{d}$ soil dry density $\left(\mathrm{g} / \mathrm{cm}^{3}\right), w$ water content (decimal entry), N SPT no of blows, and $\mathrm{N}_{60}$ adjusted SPT N value to $60 \%$ of energy

From Eq. (1), $C\left(X_{o}, X_{c}\right)$ ranges between 0 and 1 . When its value is more close to 0 , it indicates that there is a better degree of consistency between the correlated and observed parameters and that the correlation is more credible.

The TIC is simple and easy to understand but it suffers of many flaws which have been discussed in detail by Song et al. [28]. The amended TIC model proposed by Song et al. 
Table 2 Internal friction angle empirical correlations

\begin{tabular}{|c|c|c|c|c|c|}
\hline Cor. ID & Name & Formulae & Soil type & Reference & Notes \\
\hline P01 & Roy and Dass [26] & $\emptyset_{d}=34.2 \gamma_{b}-29.57$ & $\begin{array}{l}\text { Cohesionless soils in in } \\
\text { Sisra, India }\end{array}$ & [26] & $R=0.99$ \\
\hline P02 & Roy and Dass [26] & $\emptyset_{d}=44.2 \gamma_{d}-41.74$ & $\begin{array}{l}\text { Cohesionless soils in in } \\
\text { Sisra, India }\end{array}$ & [26] & $R=0.86$ \\
\hline P03 & Roy and Dass [26] & $\emptyset_{d}=1.028 w+21.53$ & $\begin{array}{l}\text { Cohesionless soils in in } \\
\text { Sisra, India }\end{array}$ & [26] & $R=0.83$ \\
\hline P04 & Meyerhof [16] & $\emptyset_{d}=0.15 D_{r}+28$ & General & [16] & - \\
\hline P05 & Gupta [7] & $\emptyset_{d}=0.14 D_{r}+28$ & High compressibility sand & [7] & - \\
\hline P06 & Gupta [7] & $\emptyset_{d}=0.115 D_{r}+31.5$ & $\begin{array}{l}\text { Medium compressibility } \\
\text { sand }\end{array}$ & [7] & - \\
\hline P07 & Gupta [7] & $\emptyset_{d}=0.10 D_{r}+34.5$ & Low compressibility sand & [7] & - \\
\hline P08 & Shioi and Fukui (1982) & $\emptyset_{d}=15+\sqrt{18 N_{70}^{\prime}}$ & For roads and bridges & [2] & - \\
\hline P09 & Shioi and Fukui (1982) & $\emptyset_{d}=0.36 N_{70}+27$ & For buildings & [2] & - \\
\hline P10 & Peck et al. (1953) & $\emptyset_{d}=\sqrt{0.3 N}+27$ & General & [21] & - \\
\hline P11 & $\begin{array}{l}\text { Munenori and Akihiko } \\
\text { (1996) }\end{array}$ & $\emptyset_{d}=\sqrt{20 N}+18$ & For sandy soils & [9] & - \\
\hline P12 & Suzuki et al. [29] & $\emptyset_{d}=\sqrt{12 N}+25$ & For gravelly soils & [29] & - \\
\hline P13 & Hatanaka and Uchida [9] & $\emptyset_{d}=20+\sqrt{15.4\left(N_{1}\right)_{60}}$ & $\begin{array}{l}\text { Clean quartz to siliceous } \\
\text { sand }\end{array}$ & [15] & - \\
\hline P14 & Meyerhof (1976) & $\emptyset_{d}=\frac{10 N}{35}+27$ & General & [14] & - \\
\hline P15 & Ohsaki et al. (1959) & $\emptyset_{d}=\sqrt{20 N}+15$ & General & {$[20]$} & - \\
\hline
\end{tabular}

$\emptyset_{d}$ drained internal friction angle, $\gamma_{b}$ bulk density $\left(\mathrm{g} / \mathrm{cm}^{3}\right), \gamma_{d}$ dry density $\left(\mathrm{g} / \mathrm{cm}^{3}\right), w$ water content $(\%), D_{r}$ relative density (\%), $N$ SPT N value, $N^{\prime}{ }_{70}$ adjusted SPT N value to $70 \%$ of energy and overburden pressure of $100 \mathrm{kPa}, \mathrm{N}_{60}$ adjusted SPT N value to $60 \%$ of energy

[28] covers many of the TIC method flaws especially the position and trend differences between the observed and correlated values so it will be used in this study.

\section{Position conformity}

For the position conformities between the observed $\left(x_{0}\right)$ and correlated $\left(x_{c}\right)$ values, the following equation is used:

$$
D\left(X_{o}, X_{c}\right)=e^{-\xi C\left(X_{o}, X_{c}\right)}
$$

where D represents the position conformity, $\xi$ is the model parameter and it will be taken $=1.0$ because all the used correlation has the same weight for position conformity. For number $(n)$ of observed values $\left(x_{o}\right)$ and correlated values $\left(x_{c}\right)$, the TIC is given by and $C\left(X_{o}, X_{c}\right)$ is defined as:

$$
C\left(X_{o}, X_{c}\right)=\left\{\begin{array}{cl}
\frac{\sqrt{\sum_{i=1}^{n}\left(x_{o}(i)-x_{c}(i)\right)^{2}}}{\sqrt{\sum_{i=1}^{n} x_{o}(i)^{2}}}, & \sqrt{\sum_{i=1}^{n} x_{o}(i)^{2}} \neq 0 \\
\sqrt{\sum_{i=1}^{n} x_{c}(i)^{2}}, & \sqrt{\sum_{i=1}^{n} x_{o}(i)^{2}}=0
\end{array}\right.
$$

where $\mathrm{n}$ is the number of observation points, $x_{o}$ is the observed values, and $x_{c}$ is the correlated values. 
$D\left(X_{o}, X_{c}\right)$ value ranges between 0 and 1 . When it is close to 1 , it indicates better consistency between the position of the correlated and observed values.

\section{Trend conformity}

For the trend conformities between the observed and correlated values, the following equation is used:

$$
T\left(X_{o}, X_{c}\right)=e^{-\lambda \delta\left(X_{o}^{\prime}, X_{c}^{\prime}\right)}
$$

where $\mathrm{T}$ represents the trend conformity, $\lambda$ is the model parameter $=1$ (because all correlations have the same weight), and $\delta\left(X_{c}^{\prime}, X_{o}^{\prime}\right)$ is defined as:

$$
\delta\left(X_{o}^{\prime}, X_{c}^{\prime}\right)=\left\{\begin{array}{cc}
\frac{\sqrt{\sum_{i=1}^{n-1}\left(x_{o}^{\prime}(i)-x_{c}^{\prime}(i)\right)^{2}}}{\sqrt{\sum_{i=1}^{n-1} x_{o}^{\prime}(i)^{2}}}, & \sqrt{\sum_{i=1}^{n-1} x_{o}^{\prime}(i)^{2}} \neq 0 \\
\sqrt{\sum_{i=1}^{n-1} x_{c}^{\prime}(i)^{2}}, & \sqrt{\sum_{i=1}^{n-1} x_{o}^{\prime}(i)^{2}}=0
\end{array}\right.
$$

where $\mathrm{n}$ is the number of observation points, $x_{o}^{\prime}$ is the observed values' first derivative, and $x_{c}^{\prime}$ is the correlated values' first derivative. $T\left(X_{o}, X_{c}\right)$ value ranges between 0 and 1 . When it is close to 1 , it indicates better consistency between the trend of correlated and observed values.

\section{Integration of position and trend conformities}

For selecting the most credible correlation, the degrees of consistency between the observed values and all correlated values should consider both position and trend conformities at the same time. Principal component analysis is used to correlate between $D\left(X_{o}, X_{c}\right)$ and $T\left(X_{o}, X_{c}\right)$ to have a single value that be used for correlations ranking as follows:

$$
S_{i j}=\frac{a_{i j}}{a_{\cdot j}}
$$

where $S_{i j}$ is the standardized position and trend conformity; $j=1$ for position conformity or 2 for trend conformity; $a_{i 1}=D\left(X_{o}, X_{c}\right) ; a_{i 2}=T\left(X_{o}, X_{c}\right)$; and $a_{. j}=\frac{\sum_{i=1}^{p} a_{i j}}{P}$; and $\mathrm{p}$ is the number of correlations

The covariance $(\mathrm{V})$ of the standardized position and trend conformity is a $2 \times 2 \mathrm{sym}-$ metrical matrix as follows:

$$
V=\left[\begin{array}{ll}
v_{11} & v_{12} \\
v_{21} & v_{22}
\end{array}\right]
$$

where $v_{m n}$ is the coefficient of variation $(\mathrm{CoV})$ of $\left(S_{m j}, S_{n j}\right), m=1,2$ and $n=1,2$. The ranking index $y_{j}$ based on principal component analysis can be determined from the following equation:

$$
y_{j}=k_{1} S_{j 1}+k_{2} S_{j 2}
$$

where $k_{1}$ and $k_{2}$ are the Eigen Vectors of the covariance matrix V shown in Eq. 7. 
Figure 1 summarizes the calculation procedure and equations for correlations ranking based on ATIC method.

\section{Transformation error assessment}

Uncertainties in geotechnical design parameters are inevitable due to the complex nature of the soil. Phoon and Kulhawy [23] defined the sources of uncertainties to be inherent variability $(\omega)$, measurement errors $(e)$, and transformation uncertainty $(\varepsilon)$. Phoon et al. [25] proposed a second-moment probabilistic approach (SMP) to characterize different geotechnical variabilities. SMP is complex when there is more than on measured property within the functional relationship. To overcome this complexity,

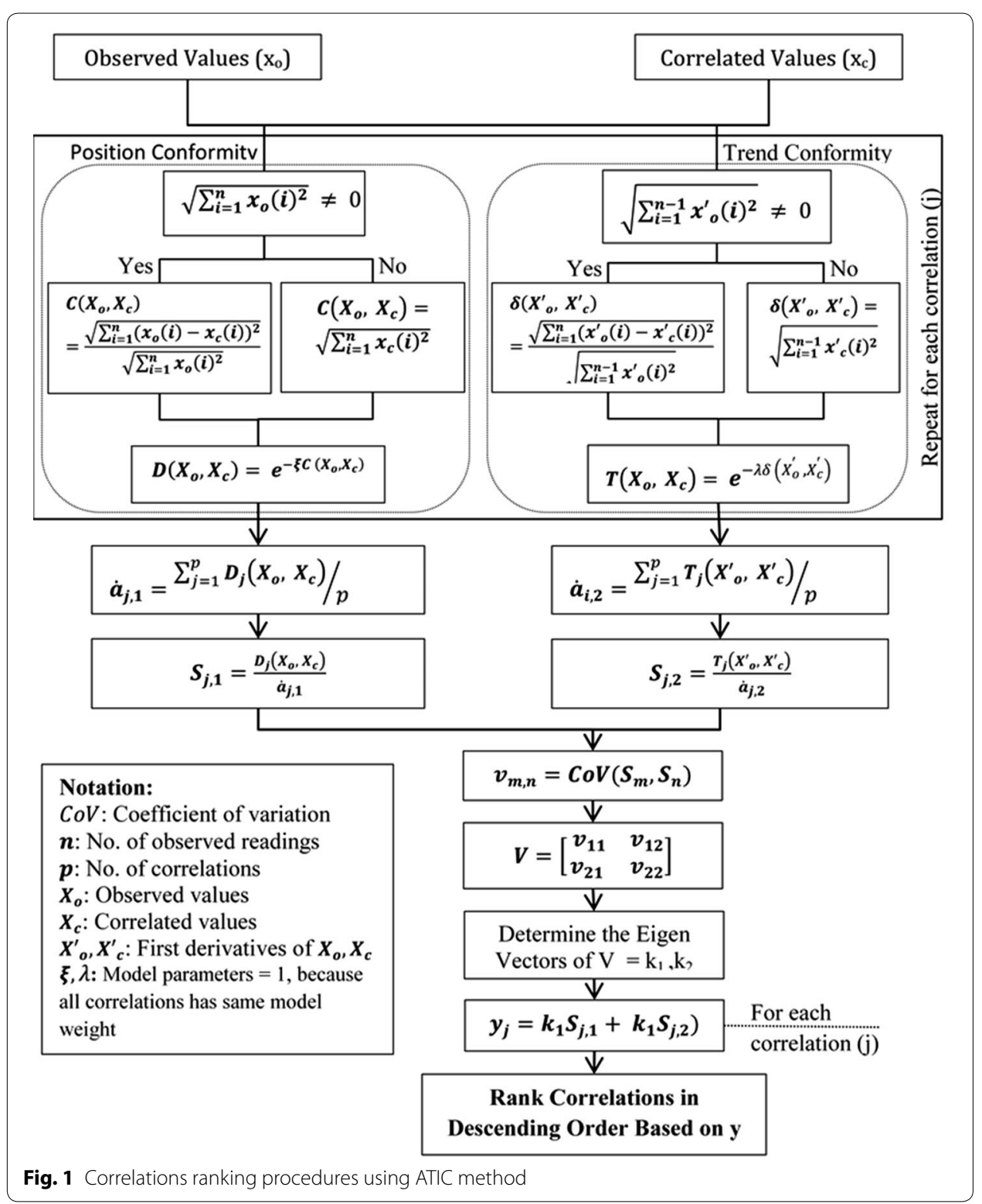


rule-based uncertainty propagation (RUP) as introduced by Farrance and Frenkel [6] to be combined with SMP is proposed (RUP-SMP).

\section{The RUP-SMP method}

If a design property, $\mathrm{y}$, is determined from input variables $\mathrm{x}_{1}, \mathrm{x}_{2}, \ldots, \mathrm{x}_{\mathrm{n}}$ through a functional relationship, then uncertainties in the x's, $\boldsymbol{u}\left(\boldsymbol{x}_{\boldsymbol{i}}\right)$, will propagate through the calculation to an uncertainty in $\mathrm{y}, u(\mathrm{y})$, equals to [6]:

$$
u^{2}(\mathrm{y})=\sum_{i=1}^{n}\left(\frac{\partial T}{\partial x_{i}}\right)^{2} u^{2}\left(x_{i}\right)
$$

Phoon et al. [25] proposed, for a design geotechnical property $\left(\xi_{d}\right)$ is determined from uncorrelated measured properties $\left(\xi_{\mathrm{mi}}\right)$ through a functional relationship has a transformation uncertainty of $(\varepsilon)$ such that:

$$
\xi_{d}=T\left(\xi_{m i}, \varepsilon\right)
$$

Knowing that the measured property $\left(\xi_{m i}\right)$ with mean value (t) contains inherent variability $(\omega)$ and measurement error (e) that can be reasonably assumed as random and uncorrelated, that is:

$$
\xi_{m i}=t_{i}+\omega_{i}+e_{i}
$$

Then the design geotechnical property can be expressed as:

$$
\xi_{d}=T\left(t_{i}+\omega_{i}+e_{i}, \varepsilon\right)
$$

By combining Eqs. (12) into (9), then uncertainties in $\left(\xi_{d}\right)$ due to the propagation of uncertainties in $\left(\xi_{\mathrm{mi}}\right)$ can be expressed as:

$$
u^{2}\left(\xi_{d}\right)=\sum_{i=1}^{n}\left\{\left(\frac{\partial T}{\partial \omega_{i}}\right)^{2} u^{2}\left(\omega_{i}\right)+\left(\frac{\partial T}{\partial e_{i}}\right)^{2} u^{2}\left(e_{i}\right)\right\}+\left(\frac{\partial T}{\partial \varepsilon}\right)^{2} u^{2}(\varepsilon)
$$

where the uncertainity $(\mathrm{u})$ can be expressed as the standard deviation $(S D)$ of the variables [30]. Knowing the values of the overall uncertainity of the design property, inherent variability and measurement error in the measured property, the transformation error can be assessed. The transformation error assessment can be used to decide if the correlated parameters are adequate for its intended purpose, if it is consistent with observed parameters, and to be used for determining the overall geotechnical uncertainty needed in reliability based analysis and design. In the following section, the proposed method for determining the transformation uncertainties is introduced as shown in Fig. 2.

\section{Directly-measured properties variability}

For soil properties that directly measured in the laboratory or in the field (e.g. liquid limit, plastic limit, bulk density, dry density, maximum and minimum dry densities,.. etc.), it is apparent that the transformation error can be assumed as zero. Equation (12) simplified to:

$$
\xi_{d}=T\left(t_{i}+\omega_{i}+e_{i}\right)
$$






Applying in Eq. (13)

$$
S D^{2}\left(\xi_{d}\right)=S D^{2}(\omega)+S D^{2}(e)
$$

Assuming a single mean value for the measured property [23], then the coefficient of variation $(\mathrm{CoV})$ can be expressed as

$$
\operatorname{CoV}^{2}\left(\xi_{d}\right)=\operatorname{CoV}^{2}(\omega)+\operatorname{CoV}^{2}(e)
$$

The overall property variability can be determined directly by determining the $S D\left(\xi_{d}\right)$ and $\operatorname{Co} V\left(\xi_{d}\right)$ of all the property's measured values for different soil types. For the same soil type at the same depth, it is reasonable to assume that the inherent variability is minimal and the variability arises only from the measurement error. To assess the measurement error, the $S D(\mathrm{e})$ and $\operatorname{CoV}(\mathrm{e})$ of the property values having same soil type and depth were determined. Then, the inherent variability will be equal to

$$
\operatorname{CoV}^{2}(\omega)=\operatorname{CoV}^{2}\left(\xi_{d}\right)-\operatorname{CoV}^{2}(e)
$$

The assumption that the inherent variability is minimum and can be neglected for same soil type and depth is not always true, especially if the distance between the boreholes is large. Some inherent variability exists due to the horizontal spatial variation. This deviation of the measurement and inherent variability values will not affect the value of the deduced transformation error because both inherent variability and measurement error are summed as shown in Eq. (16). Additional file 1: Appendix Table A1 shows the variability parameters of different directly-measured soil properties. 


\section{Directly-related properties variability}

Most of the literatures dealt with the soil properties that deduced from theoretical relations (e.g. dry density, relative density,.. etc.) as a measured property [25]; Phoon and Kulhawy $[23,24,32]$ without considering functional form effect on uncertainty propagation. Because the indirect properties have a theoretical basis, ideally, there is no transformation error. Nevertheless, some transformation error may appear due to simplification and idealization of the used theory, but these errors can be ignored [25]. Equation (13) is simplified to:

$$
u^{2}\left(\xi_{d}\right)=\sum_{i=1}^{n}\left\{\left(\frac{\partial T}{\partial \omega_{i}}\right)^{2} u^{2}\left(\omega_{i}\right)+\left(\frac{\partial T}{\partial e_{i}}\right)^{2} u^{2}\left(e_{i}\right)\right\}
$$

Thus the inherent variability of the indirect property $\boldsymbol{u}^{2}\left(\omega_{d}\right)$ is:

$$
u^{2}\left(\omega_{d}\right)=\sum_{i=1}^{n}\left\{\left(\frac{\partial T}{\partial \omega_{i}}\right)^{2} u^{2}\left(\omega_{i}\right)\right\}
$$

And the measurement error can be calculated from:

$$
u^{2}\left(\mathrm{e}_{d}\right)=\sum_{i=1}^{n}\left\{\left(\frac{\partial T}{\partial e_{i}}\right)^{2} u^{2}\left(e_{i}\right)\right\}
$$

Additional file 1: Appendix Table A2 shows the variability parameters of different directly-related soil properties.

\section{Correlation transformation error}

The transformation error of shear strength correlation can be determined using RUPSMP methods by substituting the values of inherent variability and measurement error in Eq. (13). The uncertainty propagation formulae appeared in Eq. (13) is more dependent on the soil-property/correlation functional form. The functional form of different soil properties and correlations investigated in this study are summarized in Table 3. Detailed uncertainty rules for different correlations are given in Additional file 1: Appendix Table A3.

\section{Results and discussion}

\section{Correlation ranking}

\section{Undrained cohesion}

From 1447 unconfined compressive strength test, 114 records were selected to rank different undrained cohesion correlations. These sets of records were selected using SQL query from the database with the condition of having all related measured soil properties needed for the correlations shown in Table 1. The reason for this condition (Table 4) is to maintain the consistency and accuracy of the ranking procedure. Undrained cohesion correlations were ranked using the ATIC method, the principal component analysis revealed that the position conformity has more effect than trend conformity. The final rank value $\left(\mathrm{y}_{\mathrm{j}}\right)$ for each correlation is calculated based on Eq. (21). 
Table 3 Rule-based uncertainty expression for different soil functional forms

\begin{tabular}{|c|c|c|c|}
\hline ID & Functional form & Variability expression & Uncertainty rule \\
\hline U1 & $d=A x_{1}$ & $\xi_{d}=T\left(t_{x 1}+\omega_{x 1}+e_{x 1}\right)+\varepsilon$ & $\begin{array}{l}\operatorname{SD}^{2}(\xi)=\left\{S^{2}\left(\omega_{x_{1}}\right)+S^{2}\left(e_{x_{1}}\right)\right\}+S^{2}(\varepsilon) \\
\operatorname{Cov}^{2}\left(\xi_{d}\right) \approx\left\{\operatorname{Cov}^{2}\left(\omega_{x 1}\right)+\operatorname{CoV}^{2}\left(e_{N \times 1}\right)\right\}+\frac{S D^{2}(\varepsilon)}{m \xi_{d}}\end{array}$ \\
\hline U2 & $\mathrm{d}=A x_{1}^{B}$ & $\xi_{d}=T\left(t_{x 1}+\omega_{x 1}+e_{x 1}\right)+10^{\varepsilon}$ & $S D^{2}\left(\xi_{d}\right)=B^{2}\left\{S D^{2}\left(\omega_{x_{1}}\right)+S D^{2}\left(e_{x_{1}}\right)\right\}+(\ln 10)^{2} S D^{2}(\varepsilon)$ \\
\hline U3 & $\mathrm{d}=A e^{B x_{1}}$ & $\xi_{d}=T\left(t_{x 1}+\omega_{x 1}+e_{x 1}\right)+e^{\varepsilon}$ & $\operatorname{CoV}^{2}\left(\xi_{d}\right)=B^{2}\left\{S D^{2}\left(\omega_{x_{1}}\right)+S D^{2}\left(e_{x_{1}}\right)\right\}+S D^{2}(\varepsilon)$ \\
\hline U4 & $\mathrm{d}=A x_{1} \pm B$ & $\xi_{d}=T\left(t_{x 1}+\omega_{x 1}+e_{x 1}\right)+\varepsilon$ & $S D^{2}\left(\xi_{d}\right)=A^{2}\left\{S D^{2}\left(\omega_{x_{1}}\right)+S D^{2}\left(e_{x_{1}}\right)\right\}+S D^{2}(\varepsilon)$ \\
\hline U5 & $\mathrm{d}=A\left(x_{1} \pm B\right)^{C}$ & $\xi_{d}=T\left(t_{x 1}+\omega_{x 1}+e_{x 1}\right)+10^{\varepsilon}$ & $S D^{2}\left(\xi_{d}\right)=C^{2}\left\{\frac{S D^{2}\left(\omega_{x_{1}}\right)+S D^{2}\left(e_{x_{1}}\right)}{\left(\bar{x}_{1} \pm B\right)^{2}}\right\}+(\ln 10)^{2} S D^{2}(\varepsilon)$ \\
\hline U6 & $\mathrm{d}=A x_{1} \pm B x_{2}$ & $\begin{aligned} \xi_{d}= & T\left(t_{x 1}+\omega_{x 1}+e_{x 1}\right) \\
& +T\left(t_{x 2}+\omega_{x 2}+e_{x 2}\right)+\varepsilon\end{aligned}$ & $\begin{aligned} S D^{2}\left(\xi_{d}\right)= & \left\{S D^{2}\left(\omega_{x_{1}}\right)+S D^{2}\left(e_{x_{1}}\right)\right\} \\
& +\left\{S D^{2}\left(\omega_{x_{2}}\right)+S D^{2}\left(e_{x_{2}}\right)\right\}+S D^{2}(\varepsilon)\end{aligned}$ \\
\hline U7 & $d=A x_{1}\left(x_{2}^{B}\right)$ & $\begin{aligned} \xi_{d}= & T\left(t_{x 1}+\omega_{x 1}+e_{x 1}\right) \\
& * T\left(t_{x 2}+\omega_{x 2}+e_{x 2}\right) * 10^{\varepsilon}\end{aligned}$ & $\begin{aligned} \operatorname{Cov}^{2}\left(\xi_{d}\right)= & \left\{\operatorname{Cov}^{2}\left(\omega_{x_{1}}\right)+\operatorname{Cov}^{2}\left(e_{x_{1}}\right)\right\} \\
& +B^{2}\left\{\operatorname{Cov}^{2}\left(\omega_{x_{2}}\right)+\operatorname{Cov}^{2}\left(e_{x_{2}}\right)\right\} \\
& +(\ln 10)^{2} \operatorname{SD}^{2}(\varepsilon)\end{aligned}$ \\
\hline U8 & $\mathrm{d}=A x_{1}\left(e^{B x_{2}}\right)$ & $\begin{aligned} \xi_{d}= & T\left(t_{x 1}+\omega_{x 1}+e_{x 1}\right) \\
& * T\left(t_{x 2}+\omega_{x 2}+e_{x 2}\right) * e^{\varepsilon}\end{aligned}$ & $\begin{aligned} \operatorname{Cov}^{2}\left(\xi_{d}\right)= & \left\{\operatorname{Cov}^{2}\left(\omega_{x_{1}}\right)+\operatorname{Cov}^{2}\left(e_{x_{1}}\right)\right\} \\
& +B^{2}\left\{\operatorname{Cov}^{2}\left(\omega_{x_{2}}\right)+\operatorname{Cov}^{2}\left(e_{x_{2}}\right)\right\}+S^{2}(\varepsilon)\end{aligned}$ \\
\hline U9 & $\mathrm{d}=A x_{1}\left(B x_{2}+C\right)$ & $\begin{aligned} \xi_{d}= & T\left(t_{x 1}+\omega_{x 1}+e_{x 1}\right) \\
& * T\left(t_{x 2}+\omega_{x 2}+e_{x 2}\right) * 10^{\varepsilon}\end{aligned}$ & $\begin{aligned} \operatorname{CoV}^{2}\left(\xi_{d}\right)= & \left\{\operatorname{CoV}^{2}\left(\omega_{x_{1}}\right)+\operatorname{CoV}^{2}\left(e_{x_{1}}\right)\right\} \\
& +\left(\frac{B}{B \bar{x}_{2}+C}\right)^{2}\left\{S D^{2}\left(\omega_{x_{2}}\right)+S D^{2}\left(e_{x_{2}}\right)\right\} \\
& +(\ln 10)^{2} S D^{2}(\varepsilon)\end{aligned}$ \\
\hline
\end{tabular}

where $A, B$ and $C$ : constants with no uncertainty, $x_{i}$ soil property, $\bar{x}_{i}$. mean value of the soil property

$$
y_{j}=0.7793 S_{j 1}+0.6267 S_{j 2}
$$

Summary of the ranking results based on the procedures shown in Fig. 1 are given in Table 5 with some statistical measures that are commonly used for correlations evaluation.

From the results given in Table 5, the best correlation to deduce the undrained cohesion for the studied data is correlation no. C16, which was deduced by Terzaghi et al. [31] that relates the undrained cohesion with the standard penetration test $\mathrm{N}$ value. The results of this correlation are shown in Fig. 3. Figure 3a shows the correlated versus observed undrained cohesion with the values of correlation coefficient $\left(R^{2}\right)$, mean absolute deviation (MAD), and root mean square of deviation (RMSD). Figure 3b shows the frequency distribution of correlated vlues' bias with the values of average bias, bias $\mathrm{CoV}$, and ranking index (RD). The bias in the correlated undrained cohesion distribution follows a lognormal distribution as shown in Fig. 3b. It can be noted that the bias distribution is almost symmetrical around bias-value of 1.0 (the best bias value at which the correlated value is equal the observed value).

The worst-ranked correlation of the studied data is correlation C18, the results of this correlation are given in Fig. 4. Similar figures and values for the rest of correlations are given in Additional file 1: Appendix Figure A1. It can be noted that the determination 
Table 4 Undrained cohesion correlations ranking results based on ATIC method with commonly used statistical measures in correlations evaluation

\begin{tabular}{|c|c|c|c|c|c|c|c|c|c|c|}
\hline \multirow[t]{2}{*}{ Cor. ID } & \multicolumn{4}{|c|}{ ATIC method } & \multicolumn{6}{|c|}{ Statistical measures } \\
\hline & $D\left(X_{o}, X_{c}\right)$ & $T\left(X_{0}, X_{C}\right)$ & $y_{j}$ & Rank & $\mathrm{R}^{2}$ & MAD & RMSD & Bias & Bias CoV & $\mathrm{RD}$ \\
\hline $\mathrm{Cl}$ & 0.408 & 0.363 & 1.579 & 10 & 0.0052 & 88.73 & 124.63 & 8.17 & 168.73 & 15.54 \\
\hline C2 & 0.427 & 0.357 & 1.604 & 8 & 0.0065 & 85.84 & 118.59 & 6.26 & 157.18 & 11.16 \\
\hline C3 & 0.407 & 0.363 & 1.578 & 11 & 0.0026 & 88.65 & 124.96 & 8.23 & 164.01 & 15.31 \\
\hline C4 & 0.409 & 0.348 & 1.548 & 14 & 0.0383 & 91.04 & 124.48 & 7.84 & 178.10 & 15.55 \\
\hline$C 5$ & 0.246 & 0.068 & 0.630 & 18 & 0.3119 & 121.62 & 195.39 & 0.63 & 79.36 & 0.62 \\
\hline C6 & 0.485 & 0.366 & 1.738 & 4 & 0.1928 & 63.56 & 100.61 & 2.37 & 90.49 & 2.55 \\
\hline C7 & 0.517 & 0.276 & 1.608 & 7 & 0.2156 & 63.36 & 91.93 & 2.39 & 118.38 & 3.15 \\
\hline $\mathrm{C} 8$ & 0.414 & 0.361 & 1.584 & 9 & 0.0026 & 87.25 & 122.91 & 7.01 & 164.04 & 12.98 \\
\hline C9 & 0.392 & 0.369 & 1.559 & 12 & 0.1550 & 91.41 & 130.3 & 8.90 & 98.60 & 11.81 \\
\hline $\mathrm{C} 10$ & 0.389 & 0.370 & 1.556 & 13 & 0.0001 & 93.7 & 131.38 & 15.15 & 297.70 & 47.43 \\
\hline C11 & 0.367 & 0.364 & 1.501 & 15 & 0.3901 & 100.57 & 139.38 & 80.56 & 146.31 & 143.07 \\
\hline $\mathrm{C} 12$ & 0.278 & 0.086 & 0.733 & 17 & 0.0054 & 119.08 & 178.31 & 47.66 & 161.84 & 90.15 \\
\hline $\mathrm{C} 13$ & 0.433 & 0.359 & 1.621 & 6 & 0.0880 & 79.16 & 116.37 & 5.66 & 128.16 & 8.62 \\
\hline C14 & 0.489 & 0.322 & 1.651 & 5 & 0.0715 & 68.8 & 99.59 & 2.40 & 133.58 & 3.49 \\
\hline $\mathrm{C} 15$ & 0.238 & 0.210 & 0.916 & 16 & 0.5845 & 138.62 & 199.97 & 0.56 & 55.41 & 0.54 \\
\hline $\mathrm{C} 16$ & 0.610 & 0.393 & 2.042 & 1 & 0.5410 & 49.37 & 68.72 & 3.16 & 92.41 & 3.63 \\
\hline $\mathrm{C} 17$ & 0.138 & 0.085 & 0.453 & 19 & 0.5410 & 175.25 & 275.48 & 0.95 & 92.41 & 0.88 \\
\hline $\mathrm{C} 18$ & 0.124 & 0.076 & 0.406 & 20 & 0.5410 & 185.58 & 290.9 & 0.91 & 92.41 & 0.84 \\
\hline C19 & 0.577 & 0.343 & 1.870 & 3 & 0.5410 & 49.42 & 76.53 & 2.38 & 92.41 & 2.6 \\
\hline $\mathrm{C} 20$ & 0.534 & 0.416 & 1.941 & 2 & 0.5410 & 56.29 & 87.32 & 1.96 & 57.72 & 1.48 \\
\hline
\end{tabular}

where $R^{2}$ determination coefficient, $M A D$ mean absolute deviation, RMSD root mean square of deviation, Bias observed to correlated values' ratio, Bias CoV bias coefficient of variation, $R D$ ranking distance. Equations for these statistical measures are given in Additional file 1: Appendix

Table 5 Drained internal friction angle correlations ranking results based on ATIC method with commonly used statistical measures in correlations evaluation

\begin{tabular}{|c|c|c|c|c|c|c|c|c|c|c|}
\hline \multirow[t]{2}{*}{ Cor. ID } & \multicolumn{4}{|c|}{ ATIC method } & \multicolumn{6}{|c|}{ Statistical measures } \\
\hline & $D\left(X_{0}, X_{c}\right)$ & $T\left(X_{0}, X_{c}\right)$ & $y_{j}$ & Rank & $\mathrm{R}^{2}$ & MAD & RMSD & Bias & Bias CoV & $\mathrm{RD}$ \\
\hline P1 & 0.916 & 0.492 & 1.584 & 1 & 0.6095 & 2.17 & 3.02 & 0.95 & 6.32 & 0.078 \\
\hline P2 & 0.908 & 0.453 & 1.468 & 2 & 0.6084 & 2.97 & 3.3 & 1.08 & 6.30 & 0.105 \\
\hline P3 & 0.879 & 0.407 & 1.324 & 4 & 0.2732 & 3.89 & 4.44 & 0.91 & 8.79 & 0.12 \\
\hline P4 & 0.890 & 0.312 & 1.038 & 8 & 0.4410 & 3.09 & 4.01 & 0.97 & 11.96 & 0.12 \\
\hline P5 & 0.900 & 0.329 & 1.093 & 7 & 0.4410 & 2.79 & 3.63 & 0.98 & 11.22 & 0.112 \\
\hline P6 & 0.880 & 0.371 & 1.216 & 6 & 0.4410 & 3.59 & 4.39 & 0.92 & 8.70 & 0.113 \\
\hline P7 & 0.837 & 0.392 & 1.275 & 5 & 0.4410 & 5.5 & 6.11 & 0.86 & 7.79 & 0.155 \\
\hline P8 & 0.894 & 0.279 & 0.940 & 11 & 0.5345 & 2.81 & 3.86 & 1.01 & 10.59 & 0.107 \\
\hline P9 & 0.897 & 0.282 & 0.951 & 10 & 0.4938 & 2.43 & 3.75 & 0.98 & 8.98 & 0.09 \\
\hline P10 & 0.859 & 0.446 & 1.439 & 3 & 0.6199 & 4.44 & 5.21 & 1.15 & 7.74 & 0.174 \\
\hline P11 & 0.787 & 0.181 & 0.634 & 15 & 0.6199 & 6.32 & 8.2 & 0.87 & 12.53 & 0.17 \\
\hline P12 & 0.772 & 0.289 & 0.958 & 9 & 0.6199 & 7.94 & 8.87 & 0.82 & 8.90 & 0.194 \\
\hline P13 & 0.829 & 0.279 & 0.934 & 12 & 0.5345 & 5.45 & 6.43 & 0.88 & 9.20 & 0.145 \\
\hline P14 & 0.879 & 0.263 & 0.889 & 13 & 0.5712 & 2.58 & 4.42 & 1.00 & 10.10 & 0.101 \\
\hline P15 & 0.828 & 0.181 & 0.639 & 14 & 0.6199 & 4.41 & 6.45 & 0.95 & 13.58 & 0.138 \\
\hline
\end{tabular}





Fig. 3 Undrained cohesion best-ranked correlation
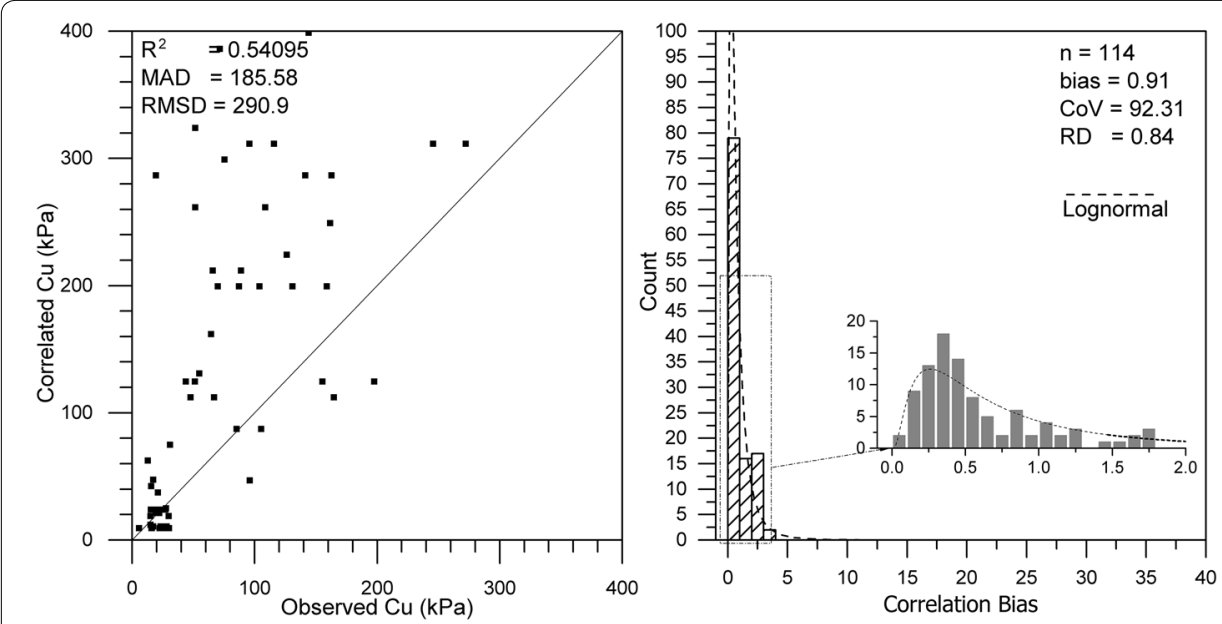

Fig. 4 Undrained cohesion worst-ranked correlation

coefficient $\left(R^{2}\right)$ for best and worst ranked correlations is equal which proof that the $R^{2}$ can't be considered alone for correlation evaluation.

\section{Internal friction angle}

The values of drained internal friction angle deduced from different empirical correlations shown in Table 2 were compared to the observed (measured) internal friction angle from direct shear box. Total number of internal friction angle records in the database were 764 records. SQL query from the database was used to collect all the internal friction angle that has a corresponding measured values for all variables needed on all correlations to maintain consistency of the correlation ranking results. The resulted number of records were 97 test groups. Correlated internal friction angles were ranked based on the methodology given in Fig. 1. The difference among the position conformities of correlations' results is not significant in contrast to the trend conformities which has 
a significant effect. So the ranking of internal friction angle correlations shall be determined primarily by the trend conformities as in Eq. (22). Summary of the ATIC method results is given in Table 5 .

$$
y_{j}=0.0968 S_{j 1}+0.9951 S_{j 2}
$$

From the results given in Table 5, the best correlation to deduce the internal friction angle from the studied data is correlation no. P01 that was proposed by Roy and Dass [26]. Figure 5 shows the correlated versus observed internal friction angle and the bias of the correlated values. The bias in the correlated internal friction angle follows a normal distribution as shown in Fig. 5b.

The worst-ranked corelation for the studied data is correlation no. P11. The results for this correlation is given in Fig. 6. Similar figures and values for the rest of correlations are given in Additional file 1: Appendix Figure A2.
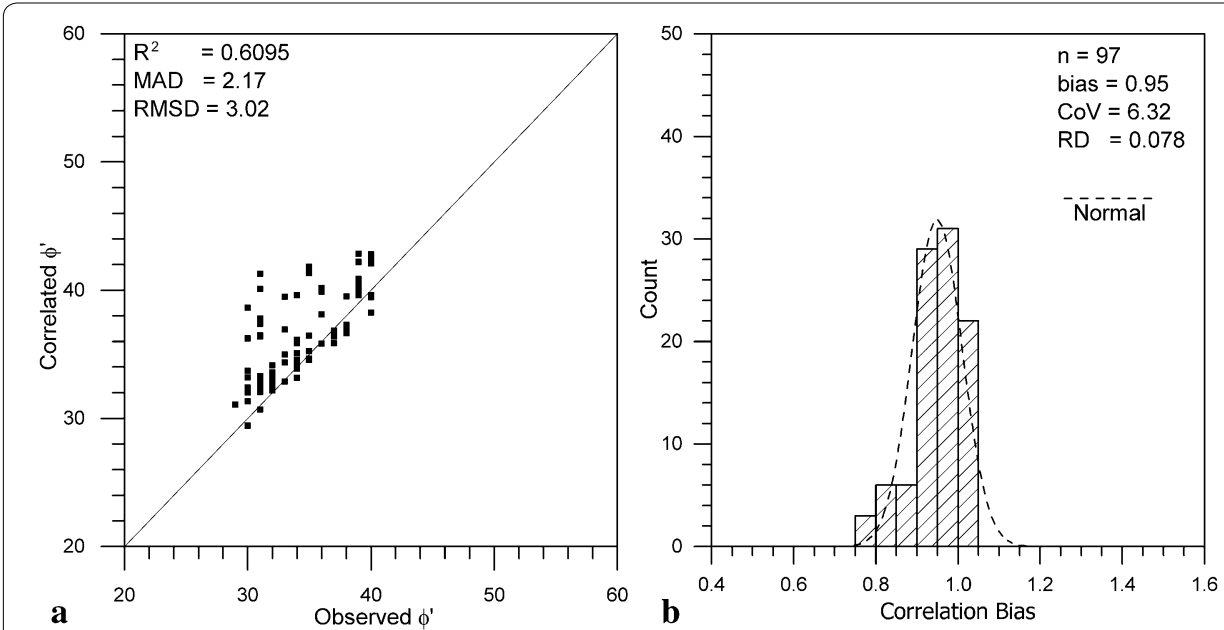

Fig. 5 Internal friction angle best-ranked correlation
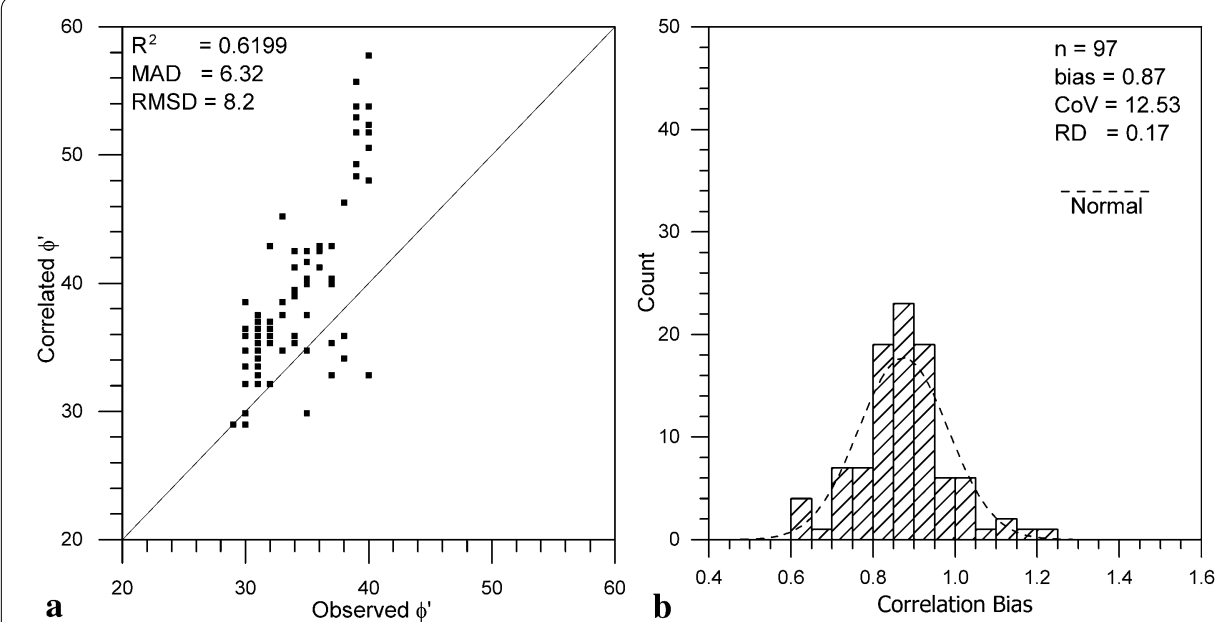

Fig. 6 Internal friction angle worst-ranked correlation 


\section{Transformation error assessment}

Geotechnical variability parameters for directly-measured and directly-related soil properties were determined based on Fig. 2 are shown in Additional file 1: Appendix Tables A1, A2. Summary of the results compared with the reported values [23] are given in Table 6.

The results of the geotechnical variabilities are in a good agreement with the literature values especially for the overall variability. Although measurement error CoV were larger than the literatures values due the large variation of the boreholes locations and involved geotechnical laboratories. In addition, the adapted methodology did not isolate completely the measurement error from the inherent variability. The directly-related soil properties has a significant deviation from the literature values especially for liquidity index because uncertainty propagation in the related properties were ignored in the literature.

Quantification of transformation error from empirical correlations is important for reliability based analysis and design [3]. In the presence of sufficient field and laboratory data, the transformation error from using different correlations can be identified. In the absence of sufficient information, Tables 7 and 8 summarize correlations' transformation error for different soil types for both undrained cohesion and internal friction angle. These values can be used as guidance for transformation error in other similar sites. The transformation error $\mathrm{CoV}$ of undrained cohesion ranges between 5 and $336 \%$. This high variation can be explained because most of the correlations are site specific and the sensitivity of undrained cohesion to soil stress history, mineral contents and site conditions. A conclusion can be made that a site-specific empirical correlation may not be applicable to another site. The transformation error for the most credible correlation $(\mathrm{C} 16)$ ranged between 16 and $95 \%$.

The transformation error $\mathrm{CoV}$ of internal friction angle ranges between 1 and $33 \%$. The transformation error for the most credible correlation (P01) ranged between 5 and $19 \%$.

Table 6 Summary of geotechnical variability compared to reported values in the literature

\begin{tabular}{|c|c|c|c|c|c|c|}
\hline \multirow[t]{2}{*}{ Soil Property } & \multicolumn{2}{|c|}{ Overall variability } & \multicolumn{2}{|c|}{ Inherent variability } & \multicolumn{2}{|c|}{ Measurement error } \\
\hline & CoV & Literature $\mathrm{CoV}^{\mathrm{a}}$ & CoV & Literature CoV & $\mathrm{CoV}$ & Literature CoV \\
\hline Bulk density & $5-9$ & $3-20$ & $2-8$ & $3-20$ & $1-8$ & $1-2$ \\
\hline Natural moisture Content & $11-55$ & $9-48$ & $7-30$ & $7-46$ & $4-45$ & $6-12$ \\
\hline Liquid limit & $7-25$ & $8-41$ & $4-15$ & $7-39$ & $5-24$ & $3-11$ \\
\hline Plastic limit & $8-24$ & $9-38$ & $4-12$ & $6-34$ & $6-23$ & $7-18$ \\
\hline Maximum dry density & $2-4$ & - & $1-2$ & - & $1-3$ & - \\
\hline Minimum dry density & $3-7$ & - & $1-6$ & - & $3-4$ & - \\
\hline $\mathrm{SPT}(\mathrm{N})$ & $22-90$ & $24-77$ & $18-80$ & $19-62$ & $13-70$ & $15-45$ \\
\hline Plasticity index & $10-35$ & $10-76$ & $6-19$ & $9-57$ & $8-33$ & $5-51$ \\
\hline Liquidity index & $57-146$ & $60-88$ & $36-96$ & $60-88$ & $44-114$ & - \\
\hline Dry density & $5-11$ & $2-13$ & $4-9$ & $2-13$ & $2-10$ & - \\
\hline Relative density & $15-35$ & $11-36$ & $6-24$ & $11-36$ & $8-18$ & - \\
\hline Overburden pressure & $7-9$ & - & $2-8$ & - & $1-8$ & - \\
\hline
\end{tabular}

a The literature CoV was deduced from Equation 16 


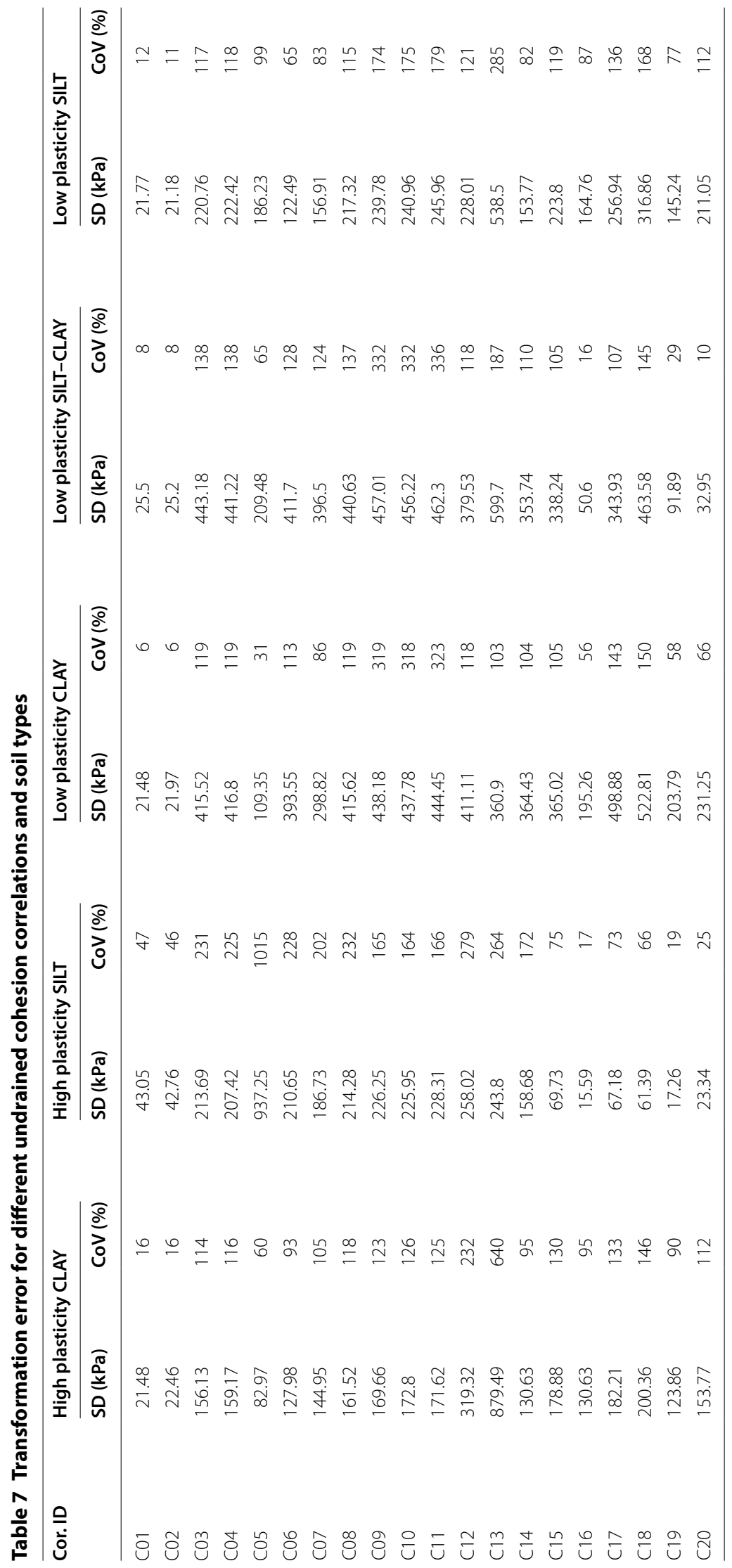


Table 8 Transformation error for different drained internal friction angle correlations and soil types

\begin{tabular}{|c|c|c|c|c|c|c|c|c|c|c|}
\hline \multirow[t]{2}{*}{ Cor. ID } & \multicolumn{2}{|c|}{$\begin{array}{l}\text { Gravelly silty } \\
\text { SAND }\end{array}$} & \multicolumn{2}{|c|}{ Silty SAND } & \multicolumn{2}{|c|}{$\begin{array}{l}\text { Silty very gravelly } \\
\text { SAND }\end{array}$} & \multicolumn{2}{|c|}{$\begin{array}{l}\text { Slightly gravelly } \\
\text { slightly silty } \\
\text { SAND }\end{array}$} & \multicolumn{2}{|c|}{$\begin{array}{l}\text { Slightly silty } \\
\text { SAND }\end{array}$} \\
\hline & $\mathrm{SD}\left(^{\circ}\right)$ & $\operatorname{CoV}(\%)$ & $\mathrm{SD}\left({ }^{\circ}\right)$ & $\operatorname{CoV}(\%)$ & $\mathrm{SD}\left({ }^{\circ}\right)$ & $\operatorname{CoV}(\%)$ & $\mathrm{SD}\left({ }^{\circ}\right)$ & $\operatorname{CoV}(\%)$ & $\mathrm{SD}\left({ }^{\circ}\right)$ & $\operatorname{CoV}(\%)$ \\
\hline P01 & 2.6 & 8 & 2.5 & 7 & 5.7 & 19 & 2.1 & 6 & 1.8 & 5 \\
\hline P02 & 2.5 & 7 & 2.6 & 7 & 1.9 & 6 & 3.9 & 12 & 2.7 & 8 \\
\hline P03 & 3.9 & 11 & 4.3 & 12 & 6.4 & 21 & 5.1 & 16 & 4.1 & 12 \\
\hline P04 & 4.0 & 12 & 1.4 & 4 & 6.1 & 20 & 1.1 & 4 & 2.8 & 8 \\
\hline P05 & 3.5 & 10 & 1.0 & 3 & 5.5 & 18 & 0.4 & 1 & 2.6 & 8 \\
\hline P06 & 4.8 & 14 & 0.9 & 3 & 7.6 & 25 & 3.8 & 12 & 3.2 & 9 \\
\hline P07 & 6.7 & 20 & 3.1 & 9 & 9.8 & 33 & 6.3 & 20 & 5.1 & 15 \\
\hline P08 & 3.9 & 11 & 4.2 & 11 & 3.5 & 12 & 2.9 & 9 & 5.2 & 15 \\
\hline P09 & 2.7 & 8 & 5.1 & 14 & 3.8 & 13 & 2.3 & 7 & 3.5 & 10 \\
\hline P10 & 5.3 & 15 & 6.5 & 18 & 0.8 & 3 & 3.4 & 11 & 5.1 & 15 \\
\hline P11 & 6.4 & 19 & 9.4 & 26 & 5.6 & 19 & 2.1 & 7 & 1.1 & 3 \\
\hline P12 & 2.5 & 7 & 10.2 & 28 & 8.7 & 29 & 7.5 & 23 & 6.4 & 19 \\
\hline P13 & 2.7 & 8 & 6.9 & 19 & 8.5 & 28 & 5.7 & 18 & 2.8 & 8 \\
\hline P14 & 5.5 & 16 & 5.6 & 15 & 1.6 & 5 & 2.8 & 9 & 3.3 & 10 \\
\hline P15 & 7.7 & 22 & 5.4 & 15 & 2.1 & 7 & 5.5 & 17 & 5.2 & 15 \\
\hline
\end{tabular}

The transformation error values shown in Tables 7 and 8 can be incorporated in the following framework to deduce the overall geotechnical variability:

1. Determine geotechnical variability (SD and $\mathrm{CoV}$ ) for directly-measured and directlyrelated soil properties using Eqs. (15) and (16) based on the procedures given in Fig. 2,

2. Identify which correlation would be used for determining shear strength parameter,

3. Use the values of correlation transformation error from Tables 7 and 8 as a guidance for the transformation error,

4. Choose the appropriate rule-based uncertainty expression from Table 3 (and Additional file 1: Appendix Table A3) based on the correlation functional form,

5. Determine the overall variability based on the chosen uncertainty expression.

\section{Conclusions}

Customized geotechnical database was created that contains 5087 boreholes from reputable geotechnical firms in Egypt, UAE, Iraq, and Indonesia. The database served to assess inherent variability, measurement error, and transformation error more consistently. The credibility and transformation error of geotechnical correlations that are commonly used to estimate undrained cohesion and internal friction angle were investigated. The correlations were ranked considering both position and trend conformity using Amended Theil Inequality Coefficient. The most credible correlation to deduce the undrained cohesion for the studied data is correlation no. C16. For internal friction angle, the most credible correlation is correlation no. P01. This conclusion is limited only to the studied data. For other sites, The proposed ATIC method can be used to determine the most crediable correlation. 
Different geotechnical variability parameters for both directly-measure and directlyrelated soil properties were determined and compared with the literature values. The overall variability of the directly-measured properties showed good agreement with the literature values. The inherent variability and measurement error showed some deviation from the literature values, especially for the natural moisture content. This variation is due to the large variation of the boreholes locations and the measurement error wasn't completely isolated from the inherent variability. This deviation didn't affect the resulted transformation error because both inherent variability and measurement error has the same weight in the uncertainty expression. The directly-related soil properties showed deviation from the literature values, especially for the liquidity index, this is due to the literature didn't consider the uncertainty propagation in the used properties.

Transformation error of different correlations was determined based on rule based uncertainty propagation method. The transformation error $\mathrm{CoV}$ of undrained cohesion's correlations ranged between 6 and $1015 \%$. This large variation shows that most of these site-specific empirical correlations may not be applicable to deduce the undrained cohesion for other sites. The transformation error for the most credible correlation (C16) ranged between 16 and $95 \%$. The small deviation of transformation error indicates that this correlation can be reasonably used to determine the undrained cohesion for the studied data. The transformation error $\mathrm{CoV}$ of internal friction angle ranges between 1 and $33 \%$. The transformation error for the most credible correlation (P01) ranged between 5 and $19 \%$.

The deduced transformation error may be used as guidance, in the absence of moreaccurate site specific values, for determining overall geotechnical variability that is needed in reliability based analysis and design. Framework for incorporating different geotechnical variabilities using rule-based uncertainty expression was introduced. This framework may be used to deduce the overall variability in a simpler way.

\section{Additional file}

Additional file 1: Appendix Additional tables and figures.

\section{Authors' contributions}

WD carried out the research work, literature review, data collection, analysis of results, and wrote the manuscript. KK studied the collected data and discuss the main findings of the research. AN and NS revised the manuscript. All authors read and approved the final manuscript.

\section{Author details}

${ }^{1}$ Egypt-Japan University of Science and Technology, P.O. Box 179, New Borg El-Arab City 21934, Egypt. ${ }^{2}$ Geo-disaster Prevention Lab., Kyushu University, Ito Campus, 744 Motoka, Nishi-Ku, Fukuoka, Fukuoka Prefecture 819-0395, Japan.

${ }^{3}$ Civil Engineering Department, Faculty of Engineering at Shoubra, Cairo, Egypt.

\section{Acknowledgements}

Waled A. Daoud is thankful to the Egyptian Ministry of Higher Education (MoHE) and Egypt_japan University of Science and Technology (E-JUST) for funding his PhD studies. Also, he would like to thank Dr. Hazem Barakat for his technical and financial support during the data collection period and special thanks to Kyushu University for offering the tools and equipment needed for the research.

\section{Competing interests}

The authors declare that they have no competing interests. 


\section{References}

1. Bjerrum L, Simons NE (1960) Comparison of shear strength characteristics of normally consolidated clays, in: research conference on shear strength of cohesive soils: 711-726

2. Bowles JE (1997) Foundation analysis and design, 5th edn. McGraw Hill, New York. doi:10.1016/0013-7952(84)90010-3

3. Ching J, Phoon K-K (2012) Establishment of generic transformations for geotechnical design parameters. Struct Saf 35:52-62. doi:10.1016/j.strusafe.2011.12.003

4. Décourt L (1989) The standard penetration test: state-of-the-art-report. Norwegian Geotechnical Institute Publication, Oslo, p 179

5. Edil TB, Benson CH (2009) Comparison of basic laboratory test results with more sophisticated laboratory and in situ tests methods on soils in Southeastern Wisconsin. Wisconsin

6. Farrance I, Frenkel R (2012) Uncertainty of measurement: a review of the rules for calculating uncertainty components through functional relationships. Clin Biochem Rev 33:49-75

7. Gupta RC (2005) Estimating moduli and friction angle from self-boring pressuremeter tests in sand. Soils Found 45:81-88

8. Hara A, Ohta T, Niwa M, Tanaka S, Banno T (1974) Shear modulus and shear strength of cohesive soils. Soils Found 14:1-12. doi:10.3208/sandf1972.14.3_

9. Hatanaka M, Uchida A (1996) Empirical correlation between penetration resistance and internal friction angle of sandy soils. Soils Found 36:1-9

10. Hettiarachchi H, Brown T (2009) Use of SPT blow counts to estimate shear strength properties of soils: energy balance approach. J Geotech Geoenviron Eng. 135:830-834

11. Jain R, Jain PK, Bhadauria SS (2010) Computational approach to predict soil shear strength. Int J Eng Sci Technol 2:3874-3885

12. Kang X, Ge L, Stephenson R (2011) Spatial variation and correlation between undrained shear strength and plasticity index, Reston: ASCE Proceedings of the geo-frontiers 2011 Conference; 2011, pp 2631-2639

13. Karlsson R, Viberg L (1967) Ratio c/p'in relation to liquid limit and plasticity index with special reference to Swedish clays. Swedish Geotechnical Institute, Linköping

14. Mayerhof GG (1976) Bearing capacity and settlement of pile foundations. J Geotech Geoenviron Eng 102

15. Mayne PW (2006) In-situ test calibrations for evaluating soil parameters, in: characterisation and engineering properties of natural soils, two volume set, vol set. Taylor \& Francis, New York

16. Meyerhof GG (1959) Compaction of sands and bearing capacity of piles. J Soil Mech Found Div 85:1-30

17. Mitchell JK, Soga K (2005) Fundamentals of soil behavior, 3rd edn. Wiley, Hoboken

18. Nassaji F, Kalantari B (2011) SPT capability to estimate undrained shear strength of fine-grained soils of Tehran Iran. Electron J Geotech Eng 16:1229-1238

19. Nixon IK (1982) Standard penetration test: state of the art report, in: Proceedings of the 2nd European Symposium on penetration testing, Amsterdam. pp 3-24

20. Ohsaki Y, Iwasaki R (1973) On dynamic shear moduli and Poisson's ratios of soil deposits. Soils Found 13:61-73

21. Peck RB, Hanson WE, Thornburn TH, Peck RB, Peck RB (1974) Foundation engineering. Wiley, New York

22. Phoon K-K (2008) Reliability-based design in geotechnical engineering: computations and applications. Taylor \& Francis Group, London

23. Phoon K-K, Kulhawy FH (1999) Characterization of geotechnical variability. Can Geotech J 36:612-624. doi:10.1139/ t99-038

24. Phoon K-K, Kulhawy FH (1999) Evaluation of geotechnical property variability. Can Geotech J 36:625-639. doi:10.1139/t99-039

25. Phoon K-K, Kulhawy FH, Grigoriu MD (1995) Reliability-based design for transmission line structure foundations. Corenell University, Ithaca

26. Roy S, Dass G (2014) Statistical models for the prediction of shear strength parameters at Sirsa India. Int J Civ Struct Eng. 4:483-498. doi:10.6088/ijcser.201404040002

27. Skempton AW, Henkel DJ (1953) The post-glacial clays of the Thames Estuary at Tilbury and Shellhaven, in: proceedings of the 3rd international conference on soil mechanics and foundation engineering. pp 302-308

28. Song J, Wei L, Ming Y (2013) A method for simulation model validation based on Theil's inequality coefficient and principal component analysis. AsiaSim. Springer, Berlin, pp 126-135

29. Suzuki Y, Shigeru G, Munenori H, Kohji T (1993) Correlation between strengths and penetration resistances for gravelly soils. Soils Found 33:92-101

30. Taylor JR (1996) An introduction to error analysis: the study of uncertainties in physical measurements. University science books, California

31. Terzaghi K, Peck RB, Mesri G (1996) Soil mechanics in engineering practice. Wiley, Hoboken

32. Villavicencio AG, Breul P, Bacconnet C, Boissier D, Espinace AR (2011) Estimation of the variability of tailings dams properties in order to perform probabilistic assessment. Geotech Geol Eng 29:1073-1084. doi:10.1007/ s10706-011-9438-5 